liver fat, in hemp seed and certain vegetables, such as tomatoes and kale, and-to a less degree-in many cereals. Beef muscle, calf brain and beef lungs desiccated at low temperature are ineffective when they form 20 per cent of the diet, but 20 per cent of dried hog liver will prevent the disease.

The antihæmorrhagic vitamin cannot be identical with $\mathrm{A}$ and $\mathrm{D}$, since very large doses of these vitamins in the form of concentrates or fish liver oils are ineffective. Commercial $(\alpha, \beta)$ carotene or 4-10 per cent of fresh wheat-germ oil do not prevent the disease, but large amounts of wheat-germ oil (24 per cent) afford some protection. 3-4 per cent of hog liver fat will completely suppress the symptoms.

The vitamin occurs in the easily soluble non-sterol fraction of the non-saponifiable matter. In hog liver fat it is not destroyed to any great extent by 12 hours heating as a layer $1-2 \mathrm{~mm}$. deep on a boiling water bath, but it appears that there is some loss during the concentration process. When the petrol-ether solution of the non-saponifiable concentrate is shaken with 90 per cent methyl alcohol, the vitamin remains in the petrol-ether. It resembles in these respects vitamin E. Further concentration by means of chromatographic adsorption and vacuum distillation using a standardisation method of Schönheyder described below is under investigation.

Since hog liver fat is many times as active as wheat-germ oil, it is very unlikely that the anti. hæmorrhagic vitamin is identical with vitamin $\mathrm{E}$. I therefore suggest the term vitamin $K$ for the antihæmorrhagic factor.

It has not been possible to demonstrate the requirement of the antihæmorrhagic vitamin for other animals than chicks, but this point is being investigated further.

Biochemical Institute,

H. DAM.

University, Copenhagen.

$$
\text { March } 19 .
$$

1 Dam, NaTvre, 133, 909; 1934.

2 Dam and Schönheyder, Biochem. J., 28, $1355 ; 1934$.

\section{Measurement and Biological action}

IN a recent paper ${ }^{1}$ a deficiency disease in chicks was described, the main symptoms of which. were a tendency to large hæmorrhages, certain pathological changes in the gizzard and anæmia. The blood of chicks suffering from this disease has a considerably prolonged clotting time, which is undoubtedly connected with these symptoms. McFarlane et al. ${ }^{2}$ have made the same observation on chicks reared on an insufficient diet.

The clotting time has been determined in the following ways: (1) The brachial vein was opened by a slight cut and $2-3 \mathrm{ml}$. blood allowed to drop slowly, during $\frac{1}{2}-\frac{3}{4}$ minute, into a small porcelain bowl. The time from the vein puncture until complete clotting is called clotting time, which for normal chicks is $\mathbf{1 - 5}$ minutes, while it may be several hours for the sick animals. In spite of the roughness of the method, it differentiates between sound and sick animals, and the results are in accordance with those obtained by the following more exact method of measuring the clotting time. (2) The carotid artery is dissected free, a cannula is inserted into the lumen of the vessel and by means of a record syringe $2-3 \mathrm{ml}$. blood is aspirated and then placed in paraffin coated tubes previously cooled to $0^{\circ} \mathrm{C}$. The tubes are centrifuged and the supernatant plasma is removed with pipettes into tubes, corked and stored in an ice box. This plasma will clot only after addition of a clotting agent (embryonic tissue or lung tissue juice).

Normal and sick plasma show an enormous difference in the clotting time under the same conditions and towards the same clotting agent (technique : Albert Fischer ${ }^{3}$ ). By increasing the concentration of the clotting agent a sick plasma can be made to clot as quickly as the normal. The concentration of the clotting agent which clots the normal plasma in $3 \mathrm{~min}$. is called 10 . That multiple of the concentration 10 which is necessary to elot a sick plasma in $3 \mathrm{~min}$. will be a quantitative expression of the morbidity of the animal. The plasma of a sick animal will become perfectly normal in a fow days by adding a sufficient amount of vitamin $K$.

The quantitative determination of vitamin $K$ is based upon the curative method. One unit of vitamin $K$ is the smallest amount which during a certain time can bring a sick animal with a certain degree of morbidity to the normal state with respect to the clotting time.

It is difficult to explain theoretically the prolonged clotting time of the blood from a sick animal since there are no morphological changes in the blood, or changes in the fibrinogen or calcium content. A change of $p \mathrm{H}$ is also not the cause. The content of the thrombokinase in the tissue of the sick animals is not reduced, nor is there any increase in the content of antiprothrombin in the plasma. The investigations have shown, however, that in normal plasma a compo. nent is present which accelerates the clotting of the plasma from sick animals, even if the concentration of the normal plasma is very small (a few per cent).

It is supposed that lack of vitamin $K$ causes a decrease of the clotting accelerating component in the blood. The nature of this component as well as its possible rôle in animal and human pathology is now under investigation.

Biochemical Institute,

University, Copenhagen. March 19

1 Dam and Schönheyder, Biochem. $J ., 28,1355 ; 1934$.
${ }^{2}$ McFarlane et al., Biochem. J., 25, 358; 1931.

${ }^{3}$ Albert Fiseher, Pfiügers Archiv, 205,$73 ;, 1930$.

\section{Loss of Velocity of Neutrons in Heavy Water}

WE have made some experiments on the Fermi effect produced in silver, when the neutrons are allowed to pass through a layer of heavy water. We used double-walled cylindrical glass vessels which could be filled with ordinary water or heavy water of 98 per cent purity. The neutron source, a tube containing radon mixed with beryllium powder, was placed in the narrow inner tube of this double-walled vessel.

The vessels were of two different sizes : the smaller ones contained $8.8 \mathrm{gm} . \mathrm{D}_{2} \mathrm{O}$ or $8 \mathrm{gm}$. $\mathrm{H}_{2} \mathrm{O}$, the difference of radii of the inner and outer cylindrical surfaces of the liquid being $9.5 \mathrm{~mm}$.; the larger vessels contained $26 \mathrm{gm} . \mathrm{D}_{2} \mathrm{O}$ or $23.4 \mathrm{gm} . \mathrm{H}_{2} \mathrm{O}$, the difference of radii being $15.5 \mathrm{~mm}$. During exposure, a silver receiver was pressed against the outer walls of the vessel surrounding the source, and the activity measured afterwards under standard conditions with 